\title{
High-dose rocuronium-induced paralysis of the adductor pollicis muscle facilitates detection of the timing for tracheal intubation in elderly patients: a randomized double-blind study
}

\author{
Shunichi Takagi ${ }^{1} \cdot$ Nami Sugaya $^{1} \cdot$ Naoto Kiuchi $^{1} \cdot$ Aya Iwasa $^{1} \cdot$ Masumi Itagaki $^{1} \cdot$ Aya Seki $^{1} \cdot$ Junko Suzuki $^{1}$. \\ Takahiro Suzuki ${ }^{1}$ (1)
}

Received: 2 June 2020 / Accepted: 18 July 2020 / Published online: 23 July 2020

(C) Japanese Society of Anesthesiologists 2020

\begin{abstract}
Purpose To prevent coughing related to tracheal intubation and the resultant exposure of intubating staff to the patients' expiratory aerosols, the timing of tracheal intubation needs to be precisely predicted. The aim of this study was to evaluate the hypothesis that the timing for safe tracheal intubation in elderly patients can be determined by acceleromyographically monitoring paralysis of the adductor pollicis muscle when high-dose rocuronium, given to block the respiratory muscles, is administered.

Methods Forty elderly (65-92 years) patients were enrolled in this study and randomly assigned to two groups, to receive rocuronium $0.6 \mathrm{mg} / \mathrm{kg}$ or $1 \mathrm{mg} / \mathrm{kg}$. After induction of anesthesia and observing acceleromyographic train-of-four (TOF) responses of the adductor pollicis muscle to ulnar nerve stimulation, the patients randomly received either dose of rocuronium. The onset times from rocuronium administration to TOF counts of 0 were measured. Soon thereafter, a single anesthesiologist who was blinded to the allocated dose of rocuronium performed laryngoscopy and tracheal intubation, and assessed intubating conditions. Data were analyzed by the unpaired $t$-test and Chi-squared test.

Results The averaged [SD] onset time of neuromuscular blockade was significantly shorter with $1 \mathrm{mg} / \mathrm{kg}$ than $0.6 \mathrm{mg} / \mathrm{kg}$ rocuronium (104.3 [30.1] s vs. 186.8 [37.5] s, $p<0.001)$. Patients who received $0.6 \mathrm{mg} / \mathrm{kg}$ rocuronium variously showed either poor $(n=9)$ or good $(n=11)$ intubating conditions. However, all patients who received $1 \mathrm{mg} / \mathrm{kg}$ rocuronium had excellent intubating conditions.

Conclusions If $1 \mathrm{mg} / \mathrm{kg}$ rocuronium is administered, a TOF count of 0 acceleromyographically observed at the adductor pollicis muscle can reveal the adequate timing for tracheal intubation.
\end{abstract}

Keywords Intubating conditions $\cdot$ Timing of intubation $\cdot$ Elderly $\cdot$ Rocuronium

\section{Introduction}

During the current critical coronavirus disease-2019 (COVID-19) pandemic, anesthesiologists have been facing the risk of perioperative infection. In particular, anesthesiologists are exposed to patients' exhaled droplets while performing tracheal intubation and extubation. To prevent dispersion of the patients' expiratory aerosol, rapid sequence

Takahiro Suzuki

suzuki.takahiro@nihon-u.ac.jp

1 Department of Anesthesiology, Nihon University School of Medicine, 30-1, Oyaguchi-Kamicho, Itabashi-Ku, Tokyo 173-8610, Japan induction and intubation (RSI) without bag-valve-mask ventilation is strongly recommended [1, 2]. However, since patients are not ventilated during RSI, their arterial oxygen content drastically decreases with prolonged intubation time [3]. Therefore, it is important to attempt laryngoscopy and tracheal intubation as soon as possible after inducing muscle paralysis. On the other hand, however, tracheal intubation might evoke vigorous coughing and bucking when the depth of neuromuscular block is not yet adequately intense. Although rocuronium has the characteristic of rapid onset of action, which is advantageous for RSI, the time to onset of rocuronium-induced neuromuscular block in elderly patients is significantly prolonged because of their lower cardiac output, varying widely between patients $[4,5]$. It is, therefore, supposed that, particularly in the elderly, 
neuromuscular monitoring to observe the onset of action of rocuronium would be helpful to determine the optimum timing of tracheal intubation, although it is a known fact that depressed single twitch or train-of-four (TOF) responses of the adductor pollicis muscle to ulnar nerve stimulation, which is usually used in clinical settings, does not accurately estimate the depth of neuromuscular block at the respiratory muscles [6]. The laryngeal muscles and diaphragm exhibit respiratory sparing effects, resulting in lower sensitivity to non-depolarizing neuromuscular blocking agents [7], although, intriguingly, they exhibit a shorter time to attain maximal neuromuscular block due to the fact that there is greater blood flow to centrally located respiratory muscles [8-10]. We hypothesized that if a sufficient dose of rocuronium, aiming to block the respiratory muscles, would be administered, simple TOF monitoring can be used to evaluate the right timing of intubation during RSI, even in elderly patients. The purpose of this study was to compare intubating conditions between aged patients receiving rocuronium $0.6 \mathrm{mg} / \mathrm{kg}(2 \bullet E D 95$ of the adductor pollicis [11]) or $1 \mathrm{mg} /$ $\mathrm{kg}$ (2•ED95 of the laryngeal muscles and diaphragm [8]), when laryngoscopy and tracheal intubation was performed immediately after the TOF responses of the adductor pollicis muscle disappeared.

\section{Methods}

The study protocol was approved by the Hospital Ethics Committee on Human Rights in Research (Nihon University Itabashi Hospital, Clinical Research Judging Committee). After registration with the University Hospital Medical Information Network (ID: UMIN000010734), 40 elderly patients ( $\geq 65$ years old) consented to participate in this study. Patients were eligible for entry into this study if they were ASA physical status I-III, and were scheduled for elective orthopedic surgery of an estimated 1-2 h duration under general anesthesia. None of the patients had evidence of a difficult airway and neuromuscular, hepatic, or renal disorders, nor were they taking any drugs known to interact with neuromuscular blocking agents. Patients whose body mass index was $>30$ or $<18.5 \mathrm{~kg} / \mathrm{m}^{2}$ were excluded from the study. The patients were equally randomized by the envelop method to the study groups receiving rocuronium $0.6 \mathrm{mg} / \mathrm{kg}$ or $1 \mathrm{mg} / \mathrm{kg}$.

All patients were routinely monitored with electrocardiogram, pulse oximeter, and non-invasive arterial pressure. Ringer's solution was intravenously (i.v) infused in the patient's forearm. Anesthesia was induced with i.v fentanyl $50-100 \mu \mathrm{g}$ and propofol $1-1.5 \mathrm{mg} / \mathrm{kg}$, while patients received $100 \%$ oxygen through an anesthesia facemask. The ulnar nerve at the wrist was stimulated at $50 \mathrm{~mA}$ intensity with square-wave stimuli of $0.2 \mathrm{~ms}$ duration, which were delivered in a train-of-four (TOF) mode at $2 \mathrm{~Hz}$ every $15 \mathrm{~s}$. Contraction of the ipsilateral adductor pollicis muscle was measured using an acceleromyograph (TOF-Watch $^{\mathrm{TM}}$, Organon Ltd., Dublin, Ireland). After calibration of the twitch responses ensured by the built-in calibration function (CAL1), the patients received an i.v bolus of rocuronium, $0.6 \mathrm{mg} / \mathrm{kg}$ or $1 \mathrm{mg} / \mathrm{kg}$, according to their group allocation. The onset times from rocuronium administration to disappearance of TOF responses were measured. Next, a single experienced anesthesiologist who performed all the intubation procedures, and who was blinded to the allocated dose of rocuronium, performed laryngoscopy and tracheal intubation, and concurrently assessed intubating conditions according to the consensus conference on good clinical research practice in pharmacodynamic studies of neuromuscular blocking agents (Table 1) [12]. A Macintosh laryngoscope and endotracheal tubes (TaperGuard ${ }^{\mathrm{TM}}$, Medtronic) ranging in inner diameter from 7.5 to $8.0 \mathrm{~mm}$ for men and $7.0-7.5 \mathrm{~mm}$ for women were used in all cases. The tube was lubricated with a small amount of $2 \%$ lidocaine gel. After confirmation of appropriate tube position, the cuff was inflated to a pressure of $25 \mathrm{mmHg}$.

Anesthesia was maintained with a continuous infusion of remifentanil $0.1-0.2 \mu \mathrm{g} / \mathrm{kg} / \mathrm{min}, 1-1.5 \%$ end-tidal concentration of sevoflurane, and fentanyl, as required. Neuromuscular block was thoroughly monitored using a TOF-Watch ${ }^{\mathrm{TM}}$

Table 1 Intubating conditions

\begin{tabular}{llll}
\hline Variable assessed & \multicolumn{2}{l}{ Clinically accepted } & Not clinically accepted \\
\cline { 2 - 3 } & Excellent & Good & Poor \\
\hline $\begin{array}{l}\text { Laryngoscopy } \\
\text { Vocal cords position }\end{array}$ & Easy & Fair & Difficult \\
$\begin{array}{l}\text { Reaction to insertion of the tracheal tube and cuff } \\
\text { inflation (Diaphragmatic movement/coughing) }\end{array}$ & Abducted & $\begin{array}{c}\text { Intermediate/ } \\
\text { moving }\end{array}$ & Closed \\
\hline
\end{tabular}

Excellent: all qualities are excellent

Good: all qualities are either excellent or good

Poor: the presence of a single quality listed under 'poor' 
during surgery and reversed with an adequate dose of sugammadex before extubation.

After the patient was completely awake, gentle endotracheal extubation was performed. When the patient was able to vocalize, the presence or absence of hoarseness was evaluated in the operating room. Hoarseness was defined as a GRBAS (grade, roughness, breathiness, asthenia, strain) scale [13] grade of 2 or 3, as described by the Japan Society of Logopedics and Phoniatrics ( 0 : no hoarseness of voice, 1 : hoarseness of voice noted by patient, 2 : mild readily apparent hoarseness of voice, 3: severe readily apparent hoarseness of voice) compared with pre-induction voice quality.

The primary endpoint was the number of cases with poor intubating conditions. We hypothesized possible incidence rates of poor intubating conditions of $50 \%$ in patients who received $0.6 \mathrm{mg} / \mathrm{kg}$ rocuronium and $10 \%$ in the $1 \mathrm{mg} / \mathrm{kg}$ group. To detect this difference with $\alpha=0.05$ and a power of 0.80 , it was necessary to include 20 patients in each study group. Data are presented as the mean [SD]. Statistical analysis was performed using the StatView ${ }^{\mathrm{TM}}$ software for Windows (SAS institute, Cary, NC, USA). The unpaired $t$-test was used for comparison of the onset times of rocuronium and patients' characteristics. Intubating conditions were analyzed by the chi-squared test. A $p$-value of $<0.05$ was considered statistically significant.

\section{Results}

Data from all 40 patients could be analyzed. Patients' characteristics were not different between the groups (Table 2). The averaged onset time was significantly shorter in the $1 \mathrm{mg} / \mathrm{kg}$ group than the $0.6 \mathrm{mg} / \mathrm{kg}$ rocuronium group (104.3 [30.1] s vs. 186.8 [37.5] s, $p<0.001)$. Tracheal intubation was successfully performed in all patients. As shown in Table 3, the number of cases with poor intubating conditions was significantly higher in the $0.6 \mathrm{mg} / \mathrm{kg}$ rocuronium group than the $1 \mathrm{mg} / \mathrm{kg}$ group $(p<0.001)$. On the other hand, all patients who received $1 \mathrm{mg} / \mathrm{kg}$ rocuronium showed excellent intubating conditions. No post-extubation hoarseness was observed in both groups.

Table 2 Patients' characteristics

\begin{tabular}{lll}
\hline & $0.6 \mathrm{mg} / \mathrm{kg}$ & $1 \mathrm{mg} / \mathrm{kg}$ \\
\hline Gender (M:F) & $10: 10$ & $10: 10$ \\
Age (y) & $73.3[8.1]$ & $72.2[5.5]$ \\
Height $(\mathrm{cm})$ & $157.5[8.5]$ & $158.3[8.4]$ \\
Weight $(\mathrm{kg})$ & $54.8[7.8]$ & $55.7[10.1]$ \\
\hline
\end{tabular}

Data are shown as mean [SD], except for gender. There are no significant differences between the two groups
Table 3 Onset times and intubating conditions

\begin{tabular}{lll}
\hline & $0.6 \mathrm{mg} / \mathrm{kg}$ & $1 \mathrm{mg} / \mathrm{kg}$ \\
\hline Onset $(\mathrm{s})$ & $186.8[37.5]$ & $104.3[30.1]^{*}$ \\
Excellent $(n)$ & 0 & 20 \\
Good $(n)$ & 11 & 0 \\
Poor $(n)$ & 9 & 0 \\
\hline
\end{tabular}

Data are shown as mean $[\mathrm{SD}] . * p<0.001$ : between groups

There is a significant difference in intubating conditions between $0.6 \mathrm{mg} / \mathrm{kg}$ and $1 \mathrm{mg} / \mathrm{kg}$ groups $(p<0.001)$

\section{Discussion}

The results of this study confirmed our hypothesis that the deep respiratory muscle blockade resulting from administration of $1 \mathrm{mg} / \mathrm{kg}$ rocuronium would be adequate to facilitate endotracheal intubation, and that the timing of the resultant disappearance of simple TOF responses at the adductor pollicis muscle could be used as an indicator of the optimum timing for tracheal intubation under excellent intubating conditions. Our method of obtaining a sufficient depth of rocuronium-induced neuromuscular block for tracheal intubation might be an effective strategy for minimization of the respiratory aerosols generated by stimulation of the patients' cough reflex. Although routine TOF monitoring can also be used to confirm the adequacy of neuromuscular blockade during RSI, an advantage of our strategy is its simplicity and the amount of time saved in monitoring, since it does not involve additional approaches to detecting a deep neuromuscular block, such as double-burst stimulation (DBS) and post-tetanic count (PTC) stimulation. It should be also recognized that disappearance of TOF responses of the thumb after an administration of rocuronium $0.6 \mathrm{mg} / \mathrm{kg}$ does not ensure sufficient paralysis of the respiratory muscles. The intubating dose of rocuronium $0.6 \mathrm{mg} / \mathrm{kg}$ is very close to $0.5 \mathrm{mg} / \mathrm{kg}$ that is the ED95 of rocuronium for neuromuscular block of the laryngeal muscles and diaphragm, it is therefore expected that the patients may cough with a certain probability during laryngoscopy and tracheal intubation even if TOF count of zero is displayed on a neuromuscular monitor applied to the adductor pollicis muscle.

Ueda and colleagues [6] reported that the absence of contractile responses to DBS and PTC stimulation could more effectively indicate the timing for excellent intubating conditions than single twitch stimulation. However, the additional time required for multiple high frequency stimulations, as used for assessment of DBS and PTC, after disappearance of a single twitch or TOF response might be disadvantageous during RSI. It is speculated that DBS is not widely and commonly applied during induction of anesthesia because of its time-consuming nature. Additionally, it was inexplicable why PTC stimulation, which is more suitable 
for demonstrating the depth of non-depolarizing neuromuscular block than DBS, is inferior in detecting the timing of excellent intubating conditions as compared to DBS. The above-mentioned study, however, used vecuronium, which has a slower onset of action, and the dose of $0.08 \mathrm{mg} / \mathrm{kg}$ administered was equivalent to $2 \bullet$ ED95 for the adductor pollicis muscle [14], but not for the laryngeal muscles and diaphragm. Their results could be related to the choice of study drug and the applied dosage. This suggestion might also support the validity of the results of the current study.

Intense neuromuscular block at the masseter, laryngeal muscles and diaphragm is needed for perfect intubating conditions [12]. Since none of the patients in this study experienced postoperative hoarseness regardless of intubating conditions, a correlation between intubating conditions and the rate of postoperative hoarseness could not be offered. However, it is generally accepted that excellent intubating conditions are less frequently associated with postoperative hoarseness and laryngeal injury $[15,16]$. When comparing the quality of tracheal intubation and incidence rate of postoperative laryngeal sequelae between induction regimens with and without neuromuscular blocking agents, it is obvious that a vigorous and sustained cough reflex is evoked in the absence of neuromuscular block, leading to inflammation of the vocal cords and tracheal mucosa. Although we cannot definitively state the reason for the absence of hoarseness in this study, it is possible that the species and dose of neuromuscular blocking agent used, additional techniques and methods related to tracheal intubation, the type and size of tube, the type of lubricant, cuff pressure, duration of anesthesia, definition of hoarseness, etc., might have been different between our study and previous studies. A previous study [17] reported that neuromuscular monitoring during induction of anesthesia increased the rate of excellent intubating conditions, but did not decrease postoperative hoarseness. This suggests that some factor other than the depth of neuromuscular block might influence the incidence of postoperative hoarseness.

Since it is difficult to directly observe neuromuscular block of the diaphragm and laryngeal muscles in clinical anesthesia practice, the corrugator supercilii muscle, which has the same sensitivity to non-depolarizing neuromuscular blocking agents as the respiratory muscles, has been used to assess the depth of deep neuromuscular block [18]. During RSI, the corrugator supercilii muscle might be more useful than the adductor pollicis muscle to more rapidly determine the right timing of tracheal intubation. Further studies are needed to assess this.

A limitation of this study is that we examined the relationship between the intubating dose of rocuronium and intubating conditions only in the elderly. Since younger patients exhibit a faster onset of action of rocuronium [19], RSI can be more quickly accomplished in younger adults. However, the frequency of poor intubating conditions observed after $0.6 \mathrm{mg} / \mathrm{kg}$ rocuronium administration might be almost as high as that of excellent conditions even in younger adult patients, because the ED95 does not differ between elderly and younger adults [20]. Second, we did not apply individual maximal current strengths for stimulation of the ulnar nerve and, instead, used a constant current of $50 \mathrm{~mA}$ in all patients. In general, a stimulus current of $50 \mathrm{~mA}$ is sufficient to obtain stable contractions of the adductor pollicis muscle [21]. However, since aged patients might have lower skin conductance and might require higher stimulus currents, it is undeniable that supramaximal stimulation currents might not have been applied in some of the study subjects. Third, the package insert of rocuronium in Japan indicates that the maximum dose of the drug for tracheal intubation should be $0.9 \mathrm{mg} / \mathrm{kg}$. However, a representative consensus guideline [1] for managing the airway in patients with COVID-19 recommends more rapid paralysis with $1.2 \mathrm{mg} / \mathrm{kg}$ rocuronium. During the current critical COVID-19 pandemic, anesthesiologists should appropriately choice the dose of rocuronium.

In conclusion, acceleromyographic observation of a TOF count of 0 at the adductor pollicis muscle after administration of $1 \mathrm{mg} / \mathrm{kg}$ rocuronium in elderly patients undergoing surgery under general anesthesia, might indicate the appropriate timing for tracheal intubation with excellent intubating conditions.

Funding Departmental funding.

\section{Compliance with ethical standards}

Conflict of interest Takagi S and Suzuki T have received speaker fees from MSD. Inc, Japan.

\section{References}

1. Cook TM, El-Boghdadly K, McGuire B, McNarry AF, Patel A, Higgs A. Consensus guidelines for managing the airway in patients with COVID-19: Guidelines from the Difficult Airway Society, the Association of Anaesthetists the Intensive Care Society, the Faculty of Intensive Care Medicine and the Royal College of Anaesthetists. Anaesthesia. 2020;75:785-99.

2. Thomas-Rüdell D, Winning J, Dickmann P, Ouart D, Kortgen A, Janssens U, Bauer M. Coronavirus disease 2019 (COVID-19): update for anesthesiologists and intensivists March 2020. Anaesthesist. 2020;24:1-10.

3. Taha SK, El-Khatib MF, Baraka AS, Haidar YA, Abdallah FW, Zbeidy RA, Siddik-Sayyid SM. Effect of suxamethonium vs. rocuronium on onset of oxygen desaturation during apnoea following rapid sequence induction. Anaesthesia. 2010;65:358-61.

4. Shiraishi N, Aono M, Kameyama Y, Yamamoto M, Kitajima $\mathrm{O}$, Suzuki T. Effects of cardiac output on the onset of rocuronium-induced neuromuscular block in elderly patients. J Anesth. 2018;32:547-50. 
5. Kameyama Y, Takagi S, Seto K, Kajiwara I, Goto M, Kitajima O, Suzuki T. Efficiency of the TOF-Cuff ${ }^{\mathrm{TM}}$ for the evaluation of rocuronium-induced neuromuscular block and its reversal with sugammadex: a comparative study vs. acceleromyography. J Anesth. 2019;33:80-4.

6. Ueda N, Muteki T, Tsuda H, Masuda Y, Ohishi K, Tobata H. Determining the optimal time for endotracheal intubation during onset of neuromuscular blockade. Eur J Anaesthesiol. 1993;10:3-8.

7. Kaneko M, Hua L. Comparison of respiratory sparing effect between pancuronium and three new nondepolarizing muscle relaxants in rats. J Anesth. 1998;12:185-8.

8. Cantineau JP, Porte F, d'Honneur G, Duvaldestin P. Neuromuscular effects of rocuronium on the diaphragm and adductor pollicis muscles in anesthetized patients. Anesthesiology. 1984;81:585-90.

9. Meistelman C, Plaud B, Donati F. Rocuronium (ORG9426) neuromuscular blockade at the adductor muscles of the larynx and adductor pollicis in humans. Can J Anaesth. 1992;39:665-9.

10. Kitajima O, Suzuki T, Fukano N, Saeki S, Ogawa S, Noda Y. Onset of rocuronium-induced neuromuscular block evaluated subjectively and acceleromyographically at the masseter muscle. J Anesth. 2011;25:376-9.

11. Kopman AF, Chin WA, Moe J. Dose-response relationship of rocuronium: a comparison of electromyographic vs. acceleromyographic-derived values. Acta Anaesthesiol Scand. 2005;49:323-7.

12. Fuchs-Buder T, Claudius C, Skovgaard LT, Eriksson LI, Mirakhur RK, Viby-Mogensen J. Good clinical research practice in pharmacodynamics studies of neuromuscular blocking agents II: the Stockholm revision. Acta Anaesthesiol Scand. 2007;51:789-808.

13. Omori K. Diagnosis of voice disorders. JMAJ. 2011;54:248-53.

14. Suzuki T, Iwasaki K, Fukano N, Hariya S, Saeki S, Ogawa S. Duration of exposure to sevoflurane affects dose-response relationship of vecuronium. Br J Anaesth. 2000;85:732-4.
15. Mencke T, Echtemach M, Kleinschmidt S, Lux P, Barth V, Plinkert PK, Fuchs-Buder T. Laryngeal morbidity and quality of tracheal intubation. Anesthesiology. 2003;98:1049-56.

16. Combes X, Andriamifidy L, Dufresne E, Suen P, Sauvat S, Scherrer E, Feiss P, Marty J, Duvaldestin P. Comparison of two induction regimens using or not using muscle relaxant: impact on postoperative upper airway discomfort. Br J Anaesth. 2007;99:276-81.

17. Mencke T, Echtemach M, Plinkert PK, Johann U, Afan N, Rensing H, Noeldge-Schomburg G, Knoll H, Larsen R. Does the timing of tracheal intubation based on neuromuscular monitoring decrease laryngeal injury? A randomized, prospective, controlled trial. Anesth Analg. 2006;102:306-12.

18. Suzuki T, Mizutani H, Miyake E, Fukano N, Saeki S, Ogawa $\mathrm{S}$. Infusion requirements and reversibility of rocuronium at the corrugator supercilii and adductor pollicis muscles. Acta Anaesthesiol Scand. 2009;53:1336-400.

19. Yamamoto S, Yamamoto Y, Kitajima O, Maeda T, Suzuki T. Reversal of neuromuscular block with sugammadex: a comparison of the corrugator supercilii and adductor pollicis muscles in a randomized dose-response study. Acta Anaesthesiol Scand. 2015;59:892-901.

20. Bevan DR, Fiset P, Balendran P, Law-Min JC, Ratcliffe A, Donati F. Pharmacodynamic behavior of rocuronium in the elderly. Can J Anaesth. 1993;40:127-32.

21. Kopman A, Lawson D. Milliamperage requirements for supramaximal stimulation of the ulnar nerve with surface electrodes. Anesthesiology. 1984;61:83-5.

Publisher's Note Springer Nature remains neutral with regard to jurisdictional claims in published maps and institutional affiliations. 